\title{
CLOSURE MECHANISMS AT THE CARDIA WITH SPECIAL REFERENCE TO THE DIAPHRAGMATICO-OESOPHAGEAL ELASTIC LIGAMENT
}

\author{
BY \\ P. M. PETERS \\ From the Central Histological Laboratory, Archway Wing, Whittington Hospital, and the Department of \\ Pathology, Royal Northern Hospital, London
}

(RECEIVED FOR PUBLICATION JULY 22, 1954)

There is much evidence that regurgitated gastric juice may injure the oesophagus, destroying the surface layers and causing inflammation in surviving tissues. The lesion referred to variously as peptic, digestion, or reflux oesophagitis is common and may be serious, even fatal, in its immediate or late effects or both. The pathology of the disease will be discussed in a later communication.

There is no general agreement at present about the nature of the closure mechanisms at the cardia, which are, as Barrett and Franklin (1949) said, " of extreme complexity." They are also, normally, most efficient. Chevalier Jackson (1922) said, “ A man may, with a stomach nominally full of liquid food, assume a position with the mouth much below the level of the stomach, swallow liquids against gravity through an oesophagus steeply slanted upward, adding to the fluid in the stomachal reservoir without any of the stomachal contents escaping." Moreover, the arrangements permit vomiting and belching when necessary, but do not usually allow coughing and straining to squeeze stomach contents up the gullet.

Three major mechanisms have been suggested:

(1) An extrinsic sphincter action of the diaphragm.

(2) An intrinsic sphincter action in the lower end of the oesophagus itself.

(3) Valve actions between the terminal oesophagus and the cardiac end of the stomach.

Other possible closure mechanisms are the effect of the positive pressure in the abdomen on the terminal oesophagus (Negus, 1943), direct pressure on the oesophagus by the lung bases, and the "liver tunnel" (Mosher, 1923) and acid control of the cardia (Cannon, 1908).

The present paper consists of a brief analysis of the literature and a report of investigations made.

\section{Diaphragmatic SPHINCTER}

Chevalier Jackson (1922) introduced the term "pinchcock" to describe this, and most later writers have agreed with him that the diaphragm does play some part at least in controlling regurgitation. In Britain the mechanism has been discussed by, among others, Abel (1929), Negus (1943), Smithers (1945), Allison (1948, 1951), Barrett and Franklin (1949), Barrett (1952), Johnstone (1952), Evans (1952), and Harman (1952). Allison (1948) considered diaphragmatic defect to be the commonest cause of reflux oesophagitis. In the present writer's experience oesophagitis does commonly follow long-standing hiatal inefficiency ; conversely, the diaphragmatic oesophagus may be partly spared when the crural tunnel is working efficiently and there is peptic oesophagitis from some other cause (e.g., chronic vomiting).

Contractions of the hiatus, synchronous with inspirations, can be felt during surgical operations (Allison, 1948, 1951), and the examining fingers are gripped when the phrenic nerve is stimulated (Wooler, 1952). Deep inspiration is known to cause retention of the barium above the diaphragm (Mosher, 1930; Lawler and McCreath, 1951； Johnstone, 1952 ; Carstairs, personal communication).

Against the pinchcock theory, Alvarez (1928) thought that the constriction of the oesophagus and the diaphragm do not coincide in radiographs (see also Harman, 1952, and Evans, 1952); also (quoting Schlippe, 1903) that the diaphragm forcibly contracts during vomiting. On the latter point, however, the work of Gold and Hatcher (1926) on cats and dogs suggests that the diaphragm may relax at the moment of expulsion of the vomit. Barrett (1952) maintained that diaphragmatic paralysis does not lead to incompetence at the cardia, but it is possible that the hiatal 
muscle is supplied by both phrenic nerves (Harrington, 1940). This was found to be the case by Leigh Collis, Satchwell, and Abrams (1954).

Accounts of the anatomy of the hiatus itself vary. Most agree that it lies in the substance of the right crus, but a few (e.g., Schatzki, 1932 ; Ducuing and Ducuing, 1934 ; Terracol, 1938) suggest that both crura form the hiatus in a figure-ofeight formation.

Many anatomy books make scanty or no reference to attachments between oesophagus and diaphragm; a few give illustrations which suggest that the oesophagus pierces the diaphragm through a tight, clean hole. It seems as though these attachments have usually been regarded in the dissecting-room as matter to be removed for the relations of other structures to be displayed. The present writer encountered the diaphragmaticooesophageal (phreno-oesophageal) ligament in a search for a possible marker to demonstrate ectopic gastric mucosa in the lower oesophagus. Laimer (1883) is cited by Schatzki (1932) and Roux (1939) as giving the first naked-eye description of the ligament, which the latter calls the "lame de Laimer." A description of its elastic structure was given by Anders and Bahrmann (1932), who considered that it secured complete "tightness" of the gullet during respiration and swallowing. Roux (1939) referred to it as a sliding sheath (véritable gaine de glissement) but did not describe its elastic composition. F. C. Lendrum (1937) found an increase in coarse elastic in the adventitia of the lower end of the oesophagus which was undoubtedly the insertion of the ligament. Harrington (1940) said the membrane normally permits some mobility of the oesophagus in swallowing and respiration and that atrophy of it (as in old age) plays a part in some hiatal herniae. Lerche (1950) and Allison (1951) considered the structure to be of considerable functional importance, although the former pointed out that its size was very variable. Barrett (1952) thought the ligament too slight to play any appreciable part in preventing sliding hiatal hernia.

Longitudinal mobility of the oesophagus, clearly of significance in relation to the elastic ligament as the tube is tethered at the proximal end, has been mentioned by several writers. Findlay and Brown Kelly (1931), for instance, found that radiographs of normal children showed that the cardia momentarily rose into the thorax as a bolus entered the stomach. Negus (1943) described contraction of the longitudinal muscle of the oesophagus in swallowing (elevation over a bolus), the mechanism being similar to that seen in snakes. Johnstone
(1952) thought that elevation of the pharynx ir节 swallowing might pull on the cardia, preparing if to relax, and influence the hiatal canal at the sames time.

\section{InTRINSIC CARDiac Sphincter}

The word "cardiac" seems to have no precises anatomical significance in relation to the alimen= tary tract. According to Lewis (1912), Galen (A.D? 130-200) introduced the term because he believe $\vec{\omega}$ apparently that similar symptoms might arise i|⿴囗十 the proximal part of the stomach and the heart芠 The old controversy concerning an intrinsic car: diac sphincter, which is understood to mean sphincter in the lower oesophagus, is partly dus to confusion of an anatomical and a physiologicaT sphincter.

Baillie (who is said to have performed a necrops $\vec{V}$ on Dr. Johnson) described an anatomical sphincte in 1807 ; and it has occasionally been reporte $\Phi$ since - for example, by Abel (1929), in a newborn. infant by Hurst $(1925,1943)$ and by Lerche $(1950$ G Most writers, however, have found no anatomicas sphincter. F. C. Lendrum (1937) did not find ong in 150 dissections, and none was seen by Rou (1939) in his detailed investigation.

A physiological sphincter, however, has beeg suggested by many-for example, Hurst and Rakg (1930), Negus (1936), Monro (1944), Allison (1951) Evans (1952), Johnstone (1952), and Harma (1952). Against this, Barrett (1952) argued that regurgitation does not complicate Heller's ope ation, in which the circular muscle of the low

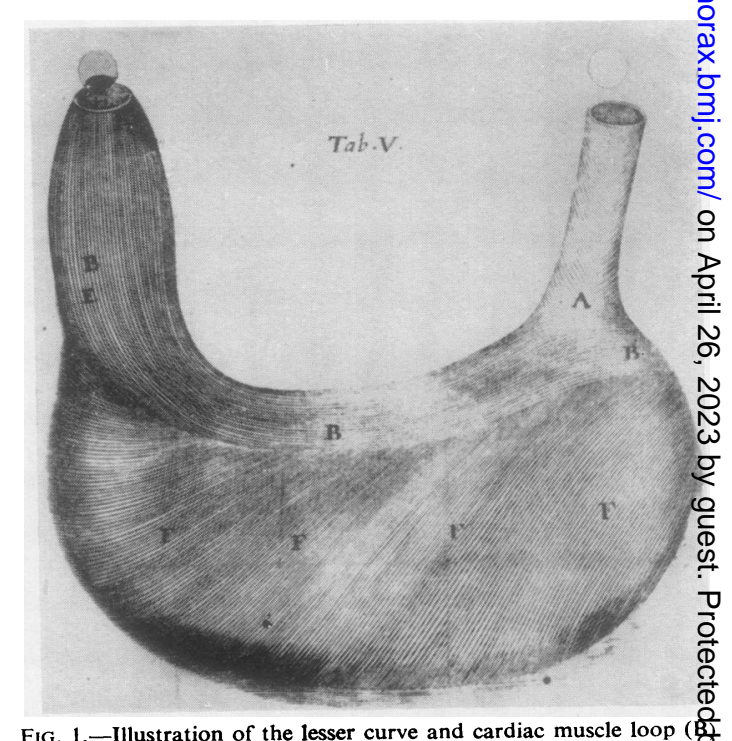

FIG. 1.-Illustration of the lesser curve and cardiac muscle loop ( rather faded, but the course of the fibres can still be made oy 
oesophagus is divided longitudinally; it seems possible, however, that resumption of function might follow healing of such an incision.

\section{Valvular Mechanisms}

Gubaroff (1886) observed that fluid could not readily be squeezed from the stomach up the oesophagus in the cadaver and thought this was due to a valve action at the incisura. (The pheriomenon can also be shown sometimes if the stomach and oesophagus are removed in one and the usual angle between them is preserved.) Of later writers who have discussed this mechanism Barrett (1952) considered it to be the sole effective one. The angle at the incisura (and the valve) is partly maintained by the gastro-phrenic ligament and partly by a loop of gastric muscle, just deep to the mucosa, which passes round the cardia and down each side of the lesser curve. This bundle of fibres was described by Helvetius in 1719 and von Aufschnaiter in 1894 (see Lerche, 1950), by Forssell (1912), and F. C. Lendrum (1937) ; in spite of the earlier writers, it has sometimes been referred to as Lendrum's loop. According to Lewis (1912), however, the earliest description came from Thomas Willis (1674), of Oxford (the

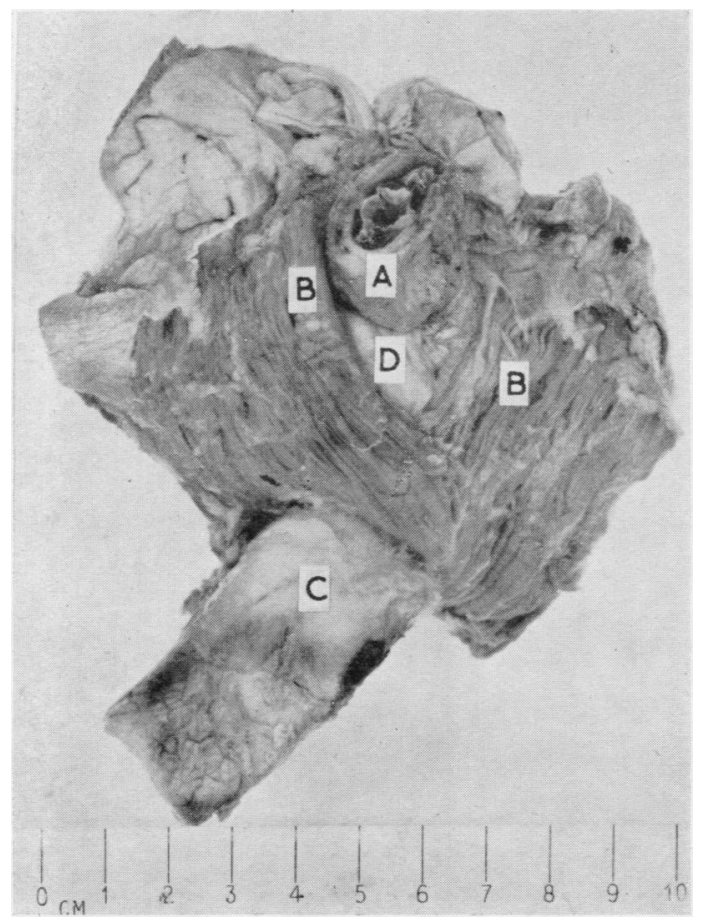

Fig. 2.-Formation of hiatus oesophageus of diaphragm by fibres of right crus (viewed from above). Dissection from an adult. A. Oesophagus. B. Hiatal muscle fibres. C. Aorta. D. Elastic A. Oesophagus. B. Hiatal muscle fibres.
diaphragmatico-oesophageal ligament.
Willis of the arterial circle), who not only described the loop but showed it in a drawing (Fig. 1). Wooler (1952) conceded that the loop played a minor part in the control of the cardia but pointed out that there was gastric mucosa in direct communication with the oesophagus above it. It may well be relevant to this that the gastric cardiac glands do not usually contain oxyntic cells and also that the distal end of the oesophagus is often particularly rich in deep mucous glands.

Ramond, Borrien, and Jacquelin (1921) and Mosher $(1923,1930)$ also found a valve action, not at the incisura, however, but in the angulation of the oesophagus at the crus of the diaphragm, therefore implying the normal existence of an abdominal oesophagus. The latter has been questioned by some (Findlay and Brown Kelly, 1931; Roux, 1939 ; Allison, 1948 ; Lerche, 1950 ; Johnstone, 1952). Allison found that gastric mucosa is seen through the oesophagoscope directly the pinchcock is passed, but it would seem that under these conditions some shortening of the gullet might occur. In view of the mobility of the oesophagus through the diaphragm, itself continuously in motion, it seems probable in fact that the amount below the diaphragm and the angle at the incisura

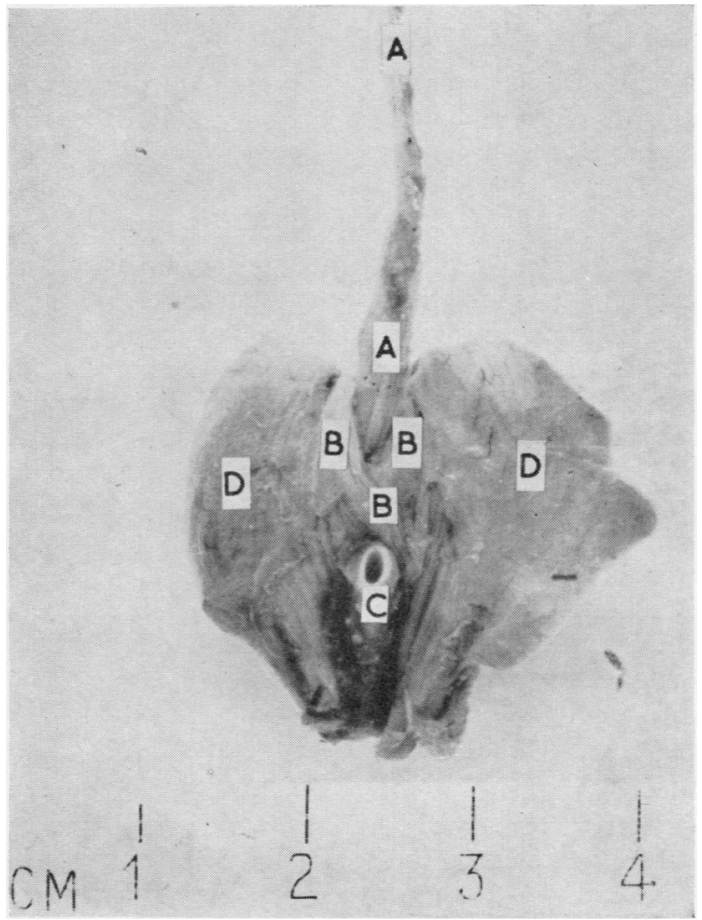

Fig. 3.-Formation of hiatus oesophageus of diaphragm by fibres of right crus (viewed from above). Dissection from normal foetus of approx. 20 weeks' gestation. A. Oesophagus. B. Hiatal muscle fibres. C. Aorta. D. Domes of diaphragm. 

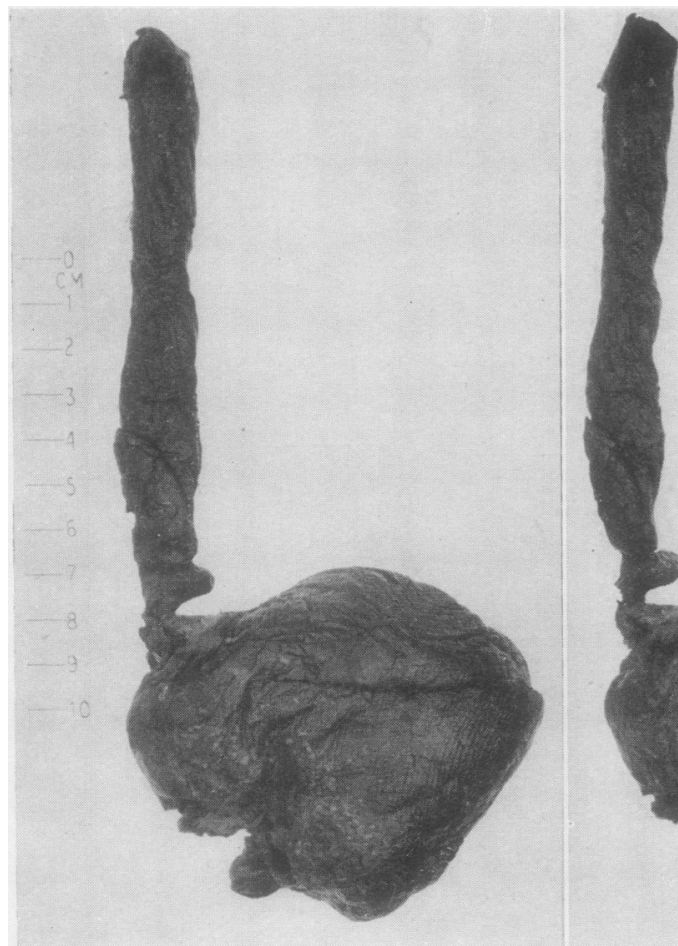

Fig. 4.

would be continually varying within a small range, and that the valve actions would vary correspondingly.

\section{Chemical Control of the Cardia}

Cannon (1908) demonstrated increase in tone of the cardiac sphincter mechanism in cats which paralleled physiological increase in gastric acidity after food. He wrote: "Thus an essential condition for digestion in the stomach, the development of an acid reaction, would automatically hold a barrier against a return of the gastric contents into the oesophagus." This important observation, though often quoted, does not appear to have been repeated or extended. For instance, does the phenomenon occur in other animals and do cases of achlorhydria in man show any particular tendency to free regurgitation?

\section{Present Investigations}

I. Dissections of hiatal structure in ten human subjects were made, in all of which the opening was found to lie in the substance of the right crus (Figs. 2 and 3). In two of these specimens fibres from the left crus appeared to contribute to the abdominal aspect of the opening and in a third a small bar of muscle from the thoracic aspect of
Figs 4, antero-posterior, and 5 三 oblique (rotated anticlockwise). -Fresh blood clot cast of part ofO stomach, cardia and oesophagus. Case of fatal haematemesis.

IG. 6.-Antero-posterior view enlarged. A. Shaded area, approximate zone of action of dia-O phragm. B. Approximate zone of action of Willis's cardiac loop.

Fig. 5.

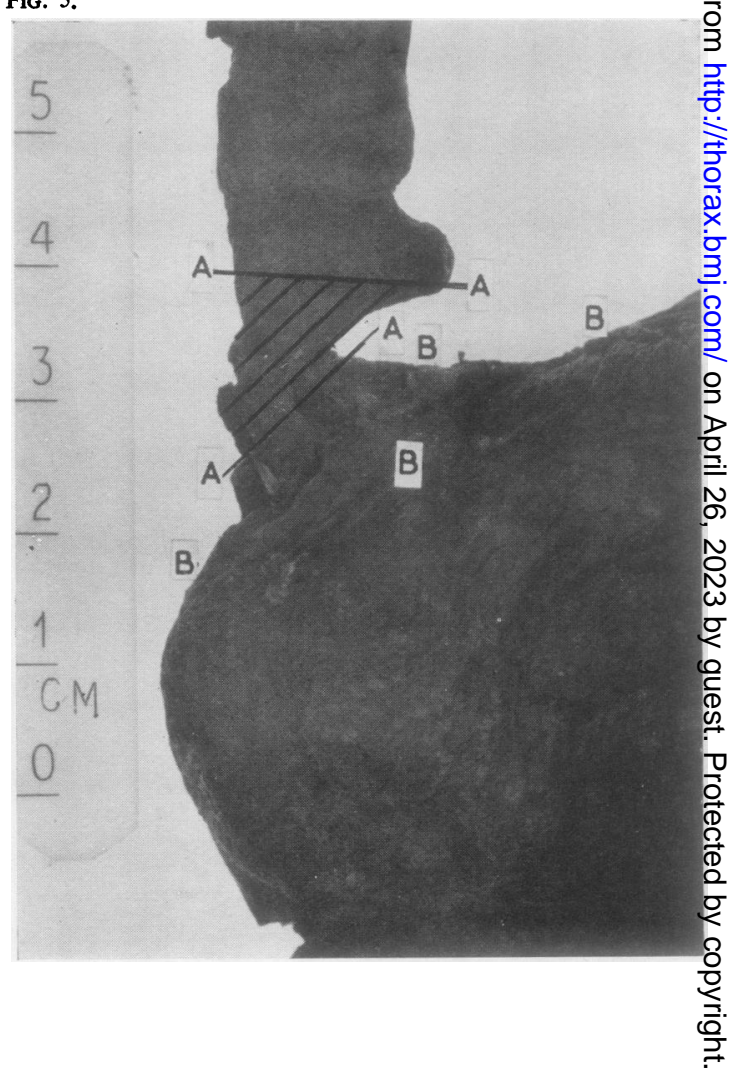


the left crus crossed to the right side close to the hiatus but did not form part of the margin. To define the types and incidence of normal variation would entail a large number of dissections, but in this small series the right crus was unquestionably the main muscle which enclosed the lower oesophagus. This anatomical feature has every appearance of functional significance. The elliptical noose of muscle encircles the oesophagus, and, with the ends tethered to bone below and to the right, it would seem inevitable that as it contracts in inspiration the contained tube would be both compressed and slightly kinked, the kinking rather in the manner and in the same axis as that produced be'ow by Willis's loop. If the left crus contributes substantially to the formation of the hiatal margin, contraction will presumably lead mainly to compression.

In published illustrations of the lower eosophageal constriction seen through the oesophagoscope (Abel, 1929; Terracol, 1938) the lumen appears as an oblique slit lying left-anterior-rightposterior, the axis thus agreeing closely with that of the hiatus. This agrees also with the appearances shown in Figs. 4, 5, and 6. The specimen is of a blood-clot cast of the oesophagus and gastric fundus removed intact at necropsy from a patient who died quickly from haemorrhage following erosion of the splenic artery by a chronic

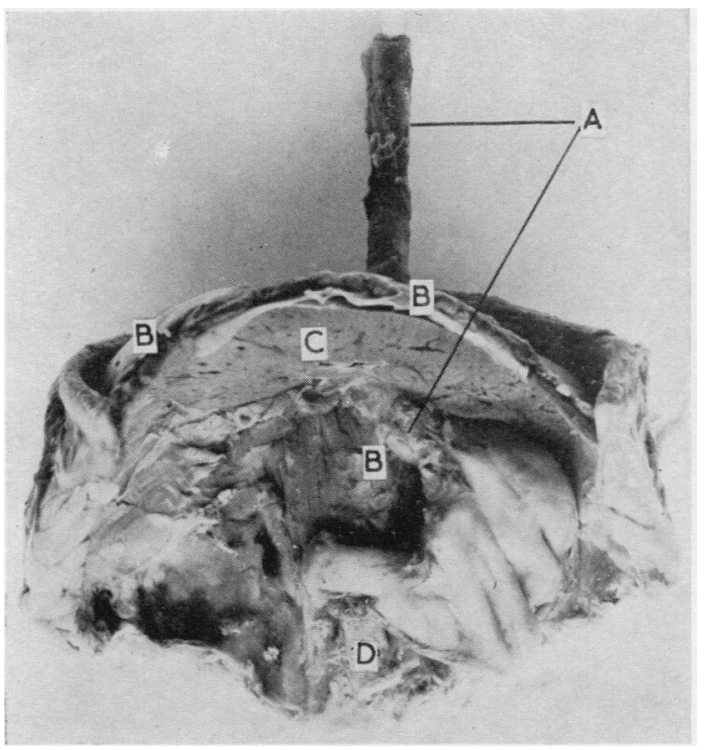

Fig. 7.-Short oblique abdominal oesophagus in 35 weeks (approx.) foetus. Fixation in situ before dissection. A. Oesophagus. B. Diaphragm. C. Liver. D. Aorta.

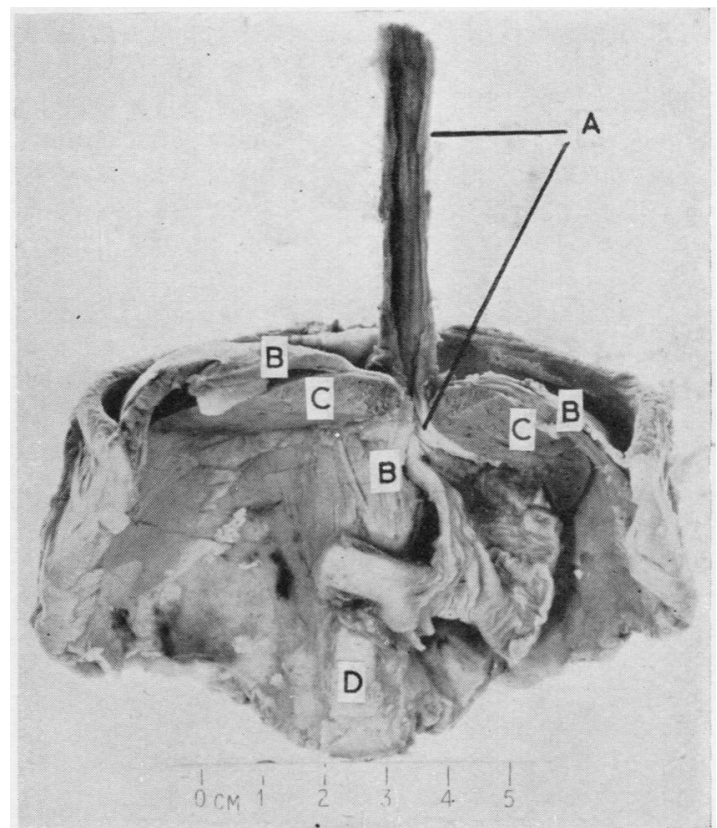

FIG. 8.-Same specimen as Fig. 7. The main constriction of the oesophagus is in the crural tunnel (see also Fig. 9), but a valvular potential is also present in angulation of the terminal oesophagus. A. Oesophagus. B. Diaphragm. C. Liver. D. Aorta.

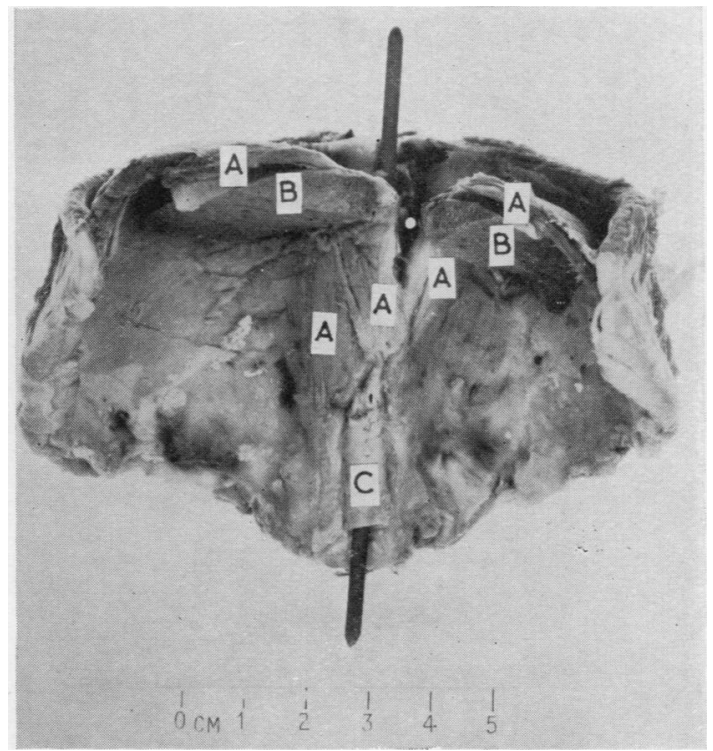

FIG. 9.-Same specimen as Figs. 7 and 8. To show length and depth of crural tunnel (white spot). A. Diaphragm. B. Liver C. Aorta. 
gastric ulcer. The constriction at the lower end of the oesophagus is clearly shown, and the axis of this constriction is demonstrated by apparent reduction in its thickness when viewed in an inclined position (partly rotated anticlockwise) as compared with the direct antero-posterior view. That the constriction was caused by the hiatus seems extremely probable from this and from its position. The specimen also shows the probable zone of action of Willis's loop.

The oesophagus and the diaphragm are related to each other on either side of the actual hiatus in the so-called crural tunnel; the extent of this is diminished when the diaphragm is detached from its bony origins. To demonstrate the full relationship a dissection was prepared as follows:

A " segment" consisting of bony thorax, thoracic viscera, diaphragm with all bony attachments, and upper abdominal viscera was removed from an infant and hardened in formalin for several weeks. Dissection was then made in stages (Figs. 7, 8, and 9). This showed the diaphragmatic domes curving steeply downwards from the horizontal plane at the summits to the more or less vertical plane at the pillars, which formed an hour-glassshaped constriction about the oesophagus with the liver fitting closely round it. This tunnel was

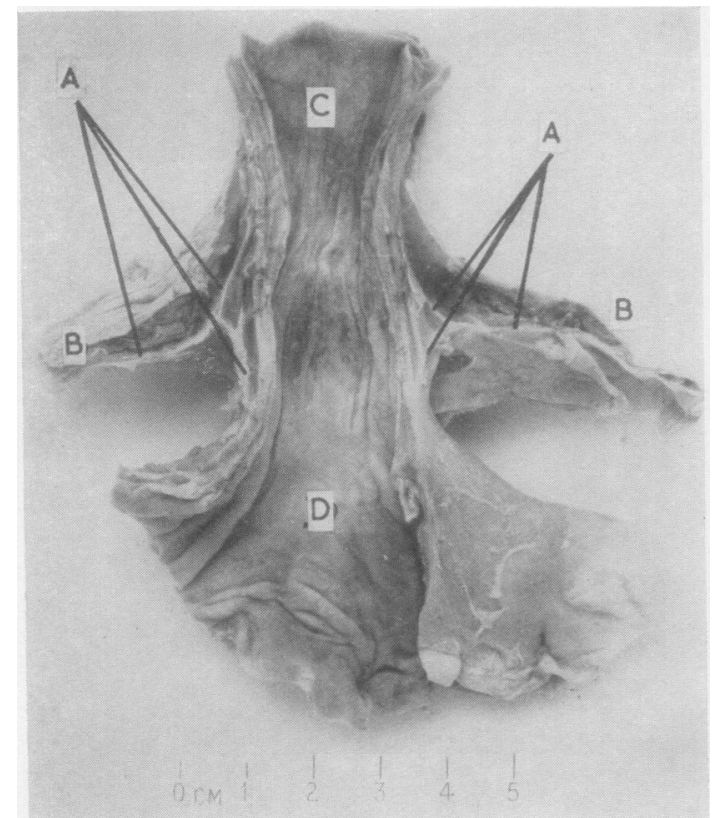

FIG. 10.-Diaphragmatico-oesophageal ligament seen in coronal section. From an adult. Note division into upward and downward insertion " cuffs." The peritoneum has been removed. A. Diaphragmatico-oesophageal ligament. B. Diaphragm. C. Oesophagus. D. Stomach. slightly oblique, the gullet just above the $\underset{\overrightarrow{3}}{\overrightarrow{0}}$ diaphragm being directly anterior to the aorta but? lying to the left of it below the hiatus. The $\frac{C}{0}$ appearances suggested that the length of the $\frac{\bar{c}}{\mathrm{~m}}$. tunnel would vary with respiration--that is, would $\vec{\sigma}$ be longest in full expiration, with the domes at $\propto$ their highest and steepest posteriorly. In fullo inspiration the proximal part of the tunnel would $\vec{\circ}$ be diminished by flattening and descent of the domes (but simultaneously the hiatal noose would $\vec{\omega}$ be contracted). It is possible that the crural tunnel is relatively longer in infancy owing to the $\times$ relatively greater bulk of the liver.

II. From several dissections made from adults, $\vec{\sim}$ children, infants, and foetuses the gross character- $-v$ istics of the average elastic diaphragmatico-oeso-음 phageal ligament appear to be as follows:

The main component arises circumferentially from the abdominal aspect of the hiatal margins and can be seen with the naked eye, after removal ${ }^{-}$ of peritoneum and subjacent fat, as a creamy $\vec{e}$ white membrane, up to about $1 \mathrm{~mm}$. thick in the

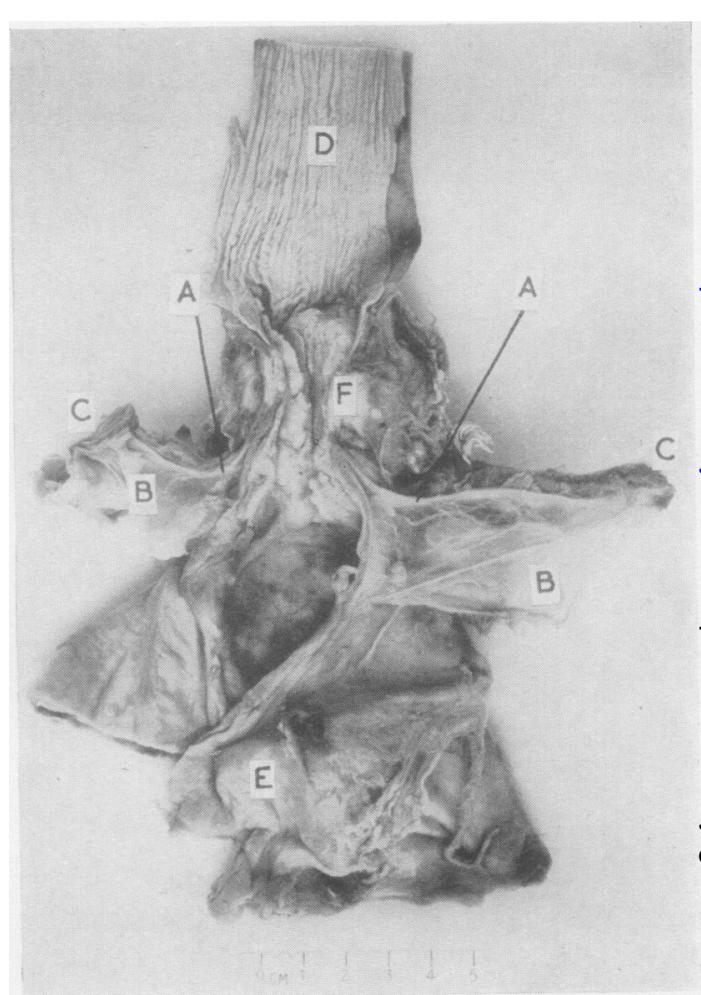

FIG. 11.-Dissection as in Fig. 10 from a case of carcinoma of lower end of oesophagus. The peritoneum has been reflected, not removed. A. Diaphragmatico-oesophageal ligament. B. Reflec $\varrho$ ted peritoneum. C. Diaphragm. D. Oesophagus. E. Stomach F. Carcinoma. 


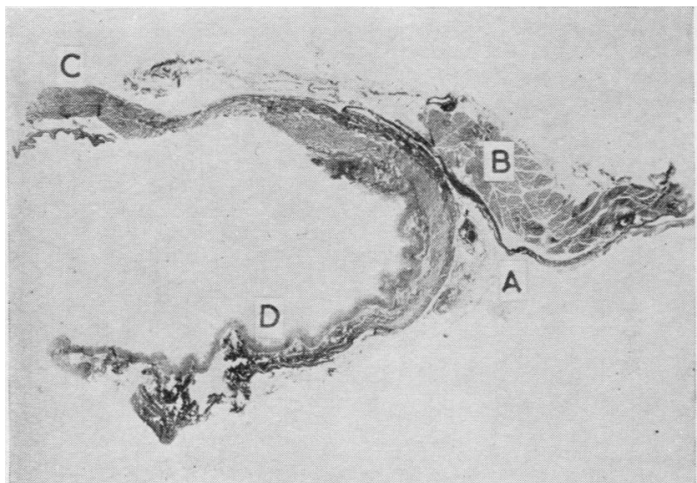

FIG. 12.-Section of normal diaphragmatico-oesophageal ligament. From an adult. ( $\times 2$. Elastic stain.) A. Diaphragmatico-oesophageal ligament. B. Diaphragm (hiatal margin). C. Lower end of oesophagus. D. Cardiac end of stomach.

adult, bridging the potential or actual space of the hiatus, to be inserted round the circumference of the oesophagus with upward and downward extensions which blend with the oesophageal adventitia (Figs. 10 and 11). It appears to be an extension of the aponeurosis of the under surface of the diaphragmatic muscle, itself forming a diaphragm within the oesophageal hiatus. The "lozengeshaped" space described by Roux would appear to be the space, possibly only a potential one in life, that lies between the upward and downward extensions of the oesophageal insertion of the membrane.

In some cases a similar extension of the thoracic aponeurosis of the diaphragm can be seen, after

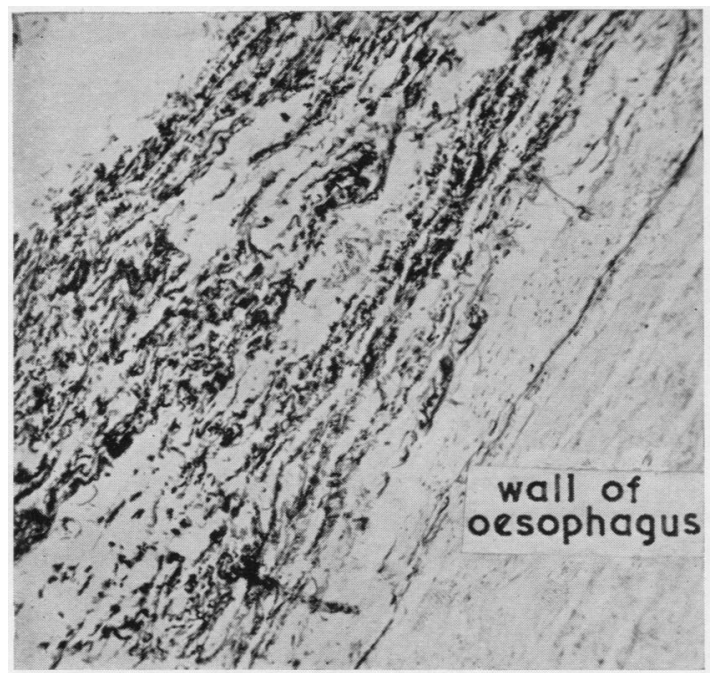

FIG. 14.-Insertion of elastic ligament in adventitia of oesophagus. $(\times 61$. Elastic stain.)

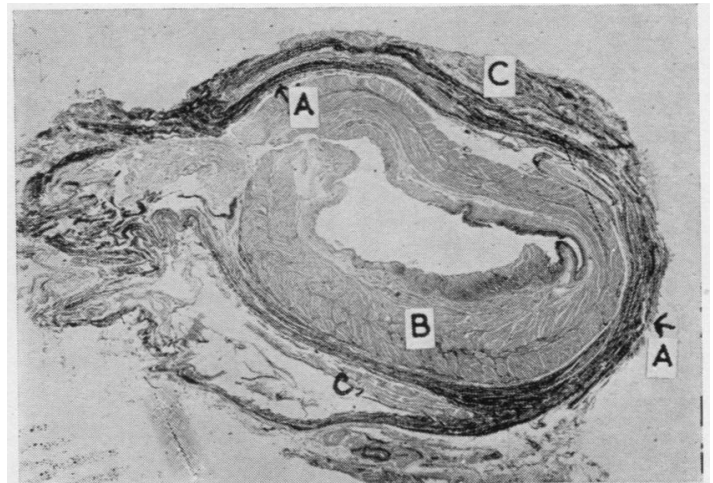

FIG. 13.-No. 29 of serial transverse sections through region of gastro-oesophageal junction. From a boy of 11 . ( $\times 4$. Elastic stain.) A. Elastic ligament. B. Gastro-oesophageal wall. C. Diaphragm.

reflection of the pleura, passing from the upper hiatal margins across the space to be inserted into the oesophageal adventitia above the main (abdominal) component. The thoracic leaf is inconstant and where present is of feebler structure than the abdominal, in conjunction with which it defines a mobile space, roughly rhomboid in section, around the diaphragmatic oesophagus. It is not surprising that the abdominal membrane is the constant and stronger element, since, owing to the positive pressure in the abdomen and the negative pressure in the thorax, the physiological requirements of drag and recoil in the two directions differ considerably. As a point of applied anatomy, it is the exact relationship of a perfora-

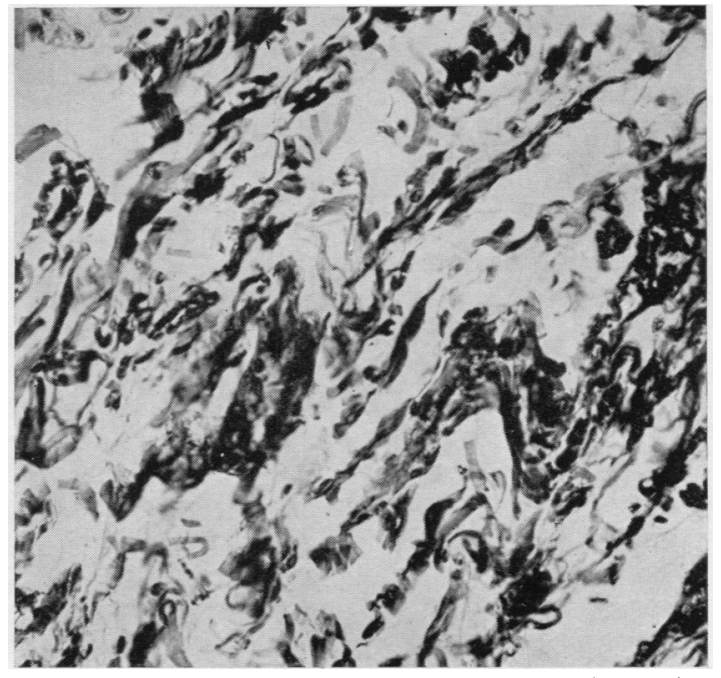

Fig. 15.-High power view of elastic fibres in diaphragmaticooesophageal ligament. $(\times 308$. Elastic stain. $)$ 


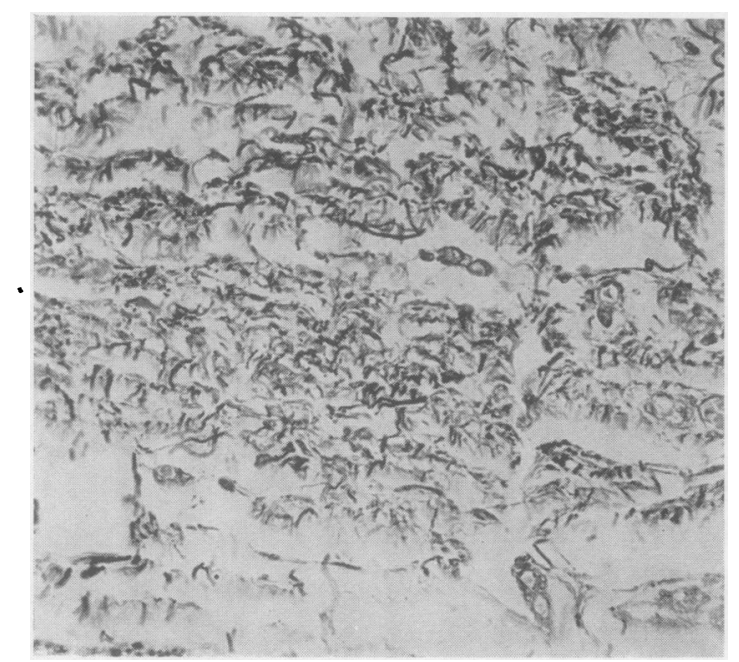

Fig. 16.-Elastic fibres in diaphragmatico-oesophageal ligament of a 30-week foetus. ( $\times 322$. Elastic stain.)

tion of the distal end of the oesophagus to the oesophageal attachment of the ligament which will largely determine whether the patient will have mediastinitis and pleurisy, or peritonitis, or both.

The hiatal membrane was studied microscopically in numerous longitudinal sections of cardia and diaphragm stained with Ehrlich's haematoxylin and eosin, Weigert's iron haematoxylin and van Gieson's mixture, and Moore's modification of French-Weigert's stain for elastin, both with neutral red counterstaining and in combination with van Gieson's mixture. The ligament is composed of coarse elastic fibres (Figs. 12-17) intimately mingled with collagen fibres in approximately equal numbers (cf. Harrington, 1940). When present the thoracic membrane is similar except that elastic fibres are relatively and absolutely less numerous. At the oesophageal insertion the main ligament divides, the terminal fibres blending proximally and distally for $2 \mathrm{~cm}$. or so with the elastic-containing adventitia of the lower oesophagus and cardiac end of the stomach. The insertion varies in relation to the oesophagogastric junction; it is close to it, within a centimetre or two, and is usually proximal but sometimes virtually coincides with it. The sheath formed by the fusion of the ligament and the oesophageal adventitia is continuous with the fibro-elastic intermuscular fascia of the gullet by fine trabeculae, which pass between bundles of the external longitudinal muscle, and is indirectly connected, by similar processes through the circularis, with the fibro-elastic submucosa.

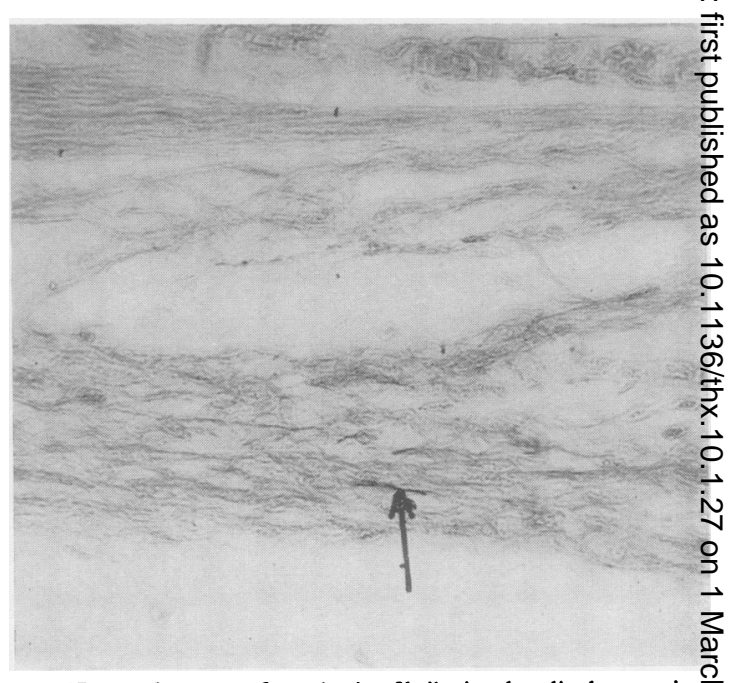

FIG. 17.-A few very fine elastic fibrils in the diaphragmaticooesophageal attachments of a 20 -week foetus. $(\times 322$. Elastic-
stain without counterstain.)

In two cases serial sections were cut transversely throughout the cardiac segment, hiatal membraneo and adjacent diaphragm and stained as above one preparation was from a stillborn infant and the other from a boy of 11 . In both instances the whole course of the hiatal membrane was traced? from its subdiaphragmatic origins, across the hiatal space (seen as a fibroelastic ring round the oesophagus in cross-section-Fig. 13) to its inser tion into the outer coat of the gullet. In the speco men from the boy a thoracic component was present, and the two leaves of the ligament were connected by trabeculae through the muscle of the diaphragm.

Observations were also made on the differentiătion of elastic fibres in the embryonic hiatal mem? brane, to obtain which serial sections were cut of two foetuses embedded in the left lateral position Very scanty and fine elastic fibrils were visible if this structure in a foetus of 20 weeks' gestation. (Fig. 17); in a 30-week foetus elastic fibres werres abundant and well formed (Fig. 16).

III. In the course of many planned dissections in infants and adults no structure resembling localized pylorus-like sphincter in the lower end of the oesophagus was found, nor has such bee seen in the healthy oesophagus in the cour@ of nearly 2,000 personally performed necropsies in which the cardiac segment has been opene longitudinally. There has been the impressiog however, that the oesophageal wall, particularR the circular muscle, is often thicker at the lower end than above (cf. Payne and Poulton, 192 
Terracol, 1938). This impression was more closely defined as follows. The oesophagus and cardiac end of the stomach were removed from several adult and infant cadavers and a strip of this from the whole or most of the length was prepared for histological examination by embedding, coiled, in one or two large paraffin blocks. If the sections did not appear to be cut cleanly at right angles, the specimen was discarded; in obliquely cut sections the muscularis looked deceptively thick. Eight satisfactory preparations were obtained and stained with Ehrlich's haematoxylin and eosin, and iron haematoxylin and van Gieson's mixture. The slides were examined macroscopically and microscopically with the following results :

(a) No localized thickening of the circular muscle coat at the lower end, as would justify the term sphincter on morphological grounds, was seen.

(b) In seven cases the circular muscle coat was judged to be slightly but definitely thicker in the distal half of the oesophagus than in the proximal; in six of these the thickening was virtually confined to the distal one-third.

In many cases of digestion oesophagitis examined by the present writer there was muscular hypertrophy as well as chronic inflammation in the lower end of the tube, mainly affecting the circular coat but sometimes the external longitudinal layer as well. The hypertrophy was usually confined to the distal $1-2$ in. $(2.5-5 \mathrm{~cm}$.) but occasionally involved much of the gullet. It is probable that to close the tube to the dangerous reflux in this disease the circular muscle at the lower end is maintained in spasm, and in time hypertrophies to result in a kind of pathologically induced elongated sphincter visible in the gross.

IV. In the dissection made in stages from an infant cadaver, illustrated in Figs. 7, 8, and 9, a short abdominal oesophagus was present, curving round the left crus to join the stomach, the angulation forming a potential valve with the crus as fulcrum.

Willis's cardiac loop was confirmed in a separate dissection from an adult.

\section{Conclusions}

In the light of the foregoing material the following tentative account of the physiology of the cardiac region is advanced.

In inspiration the diaphragm descends and, simultaneously, the positive pressure in the abdomen and the negative pressure in the thorax are increased. The mechanical tendency is for the cardiac end of the stomach to bulge up through the hiatus and for the stomach contents to be squeezed up the gullet. The anatomical arrangement of the muscular walls of the hiatus is such that this tendency is automatically checked. The oblique elliptical opening in the diaphragm is formed, for all practical purposes, by the fibres of the right crus which pass as a noose round the lower oesophagus. Contraction of this noose in inspiration, when the crural tunnel is shortened, would both compress and slightly kink the tube, the deeper the inspiration the tighter being the closure. No doubt the deep breath taken before making a heavy straining or lifting effort, particularly if this involves bending down over a full stomach, prevents regurgitation, although intraabdominal pressure (and the risk of hernia) is thereby increased. The tendency for upward displacement of the stomach in inspiration is exaggerated in vomiting and whenever intra-abdominal or intra-gastric tension is high. There is evidence also that in deglutition the oesophagus shortens as part of the mechanism of ingestion by which the tube is "elevated" over a bolus.

Another struc.ure exists in man whereby the tendency for the cardia to pass into the posterior mediastinum would be opposed, particularly when the diaphragm is relaxed in expiration. This is the diaphragmatico-oesophageal elastic ligament (membrane), a modification of the abdominal aponeurosis of the diaphragm (and therefore relatively fixed at its origin), which bridges the oesophageal hiatus and is inserted into the adventitia of the gullet as a membranous ring, with upward and downward "cuff" extensions. In some instances there is also a similar though more feeble elastic membrane arising from the pleural aspect of the diaphragm. The view is advanced that the ligament not only opposes the tendency for the cardia to pass above the diaphragm but, when this occurs physiologically, draws it down again by passive recoil : that it acts, in fact, as a centering mechanism by which the hiatal noose compresses the tube in the appropriate region (at or above the squamo-glandular mucosal junction), the two structures forming therefore a synchronized and harmonious system.

The second closure mechanism at the cardia is the still debated intrinsic cardiac sphincter. No anatomical sphincter was found in the lower end of the normal human oesophagus in this investigation, although in most specimens the circular muscle coat was found to be slightly thicker in the distal third than above. The evidence, however, favours the existence of a physiological sphincter. This is an expression of the ability of a muscular tube to close its lumen by tonic con- 
traction of its circular and spiral muscles; in the case of the lower oesophagus such contraction may possibly be initiated and maintained by stimuli from acid gastric contents and from gastric distension. In certain pathological states the circular muscle of the lower oesophagus may become hypertrophied in an attempt to prevent regurgitation.

The third main closure mechanism is the system of cardiac valves. One component of this is the oblique insertion of the oesophagus into the stomach (the valve of Gubaroff). The angle here is formed by the left wall of the oesophagus and the right wall of the gastric fundus and is maintained or increased partly by contraction of the cardiac muscle loop of Willis and partly by ballooning of the gastric fundus by the normal air bubble and its partial anchoring by the gastrophrenic ligament. The second component is formed by the turn to the left and partial twisting of the terminal oesophagus immediately below the diaphragm, the left hiatal margin and the left crus forming the fulcrum. In view of the physiological mobility of the oesophagus, it seems possible that the two valve actions may vary at different times in their relative efficacy.

To conclude, the evidence suggests that each of the three major closure mechanisms discussed in this paper normally operates in some degree and that the system as a whole is an intricate complex. Accordingly, it cannot be argued (as it often is) that a particular mechanism has played no part because its impairment does not lead to regurgitation ; adaptation of those remaining might be able to maintain comparative efficiency.

\section{SUMMARY}

(1) The main mechanisms which have been postulated for preventing regurgitation from the stomach into the oesophagus have been considered. These are :

(a) The extrinsic diaphragmatic hiatal sphincter (pinchcock, crural tunnel) working in conjunction with the elastic diaphragmatico-oesophageal ligament.

(b) The intrinsic cardiac sphincter action.

(c) The valvular mechanisms.
(2) Some aspects of the physiology of the cardiac region have been discussed.

I am much indebted to Drs. A. B. Bratton, M을 Hynes, and S. H. G. Robinson for reading the drafe and for many helpful suggestions ; also to Dr. L. $S \mathbb{D}$ Carstairs for many stimulating discussions. M thanks are due to Mr. G. W. Moore for the photo ${ }^{\mathcal{N}}$ graphs and to Miss $\mathrm{H}$. Pallan for the typing.

This paper is based on Part I of a thesis for the degree of D.M. Oxford.

\section{BIBLICGRAPHY}

Abel, A. L. (1929). Oesophageal. Obstruction. Oxford University Press, London.

Allison, P. R. (1948). Thorax, 3, 20.

_ (1951). Surg. Gynec. Obstet., 92, 419.

- (1953). Trans, med. Soc. Lond., 1951-2, 68, 15. ed. Heinemann, London.

Anders, H. E., and Bahrmann, E. (1932). Z. Klin. Med., 122, 736.

Barrett, N. R. (1952). Proc. roy. Soc. Med., 45, 279.

- and Franklin, R. H. (1949). Brit. J. Surg., 37, 194.

Cannon, W. B. (1908). Amer. J. Physiol., 23, 105.

Collis, J. Leigh, Satchwell, L. M., and Abrams, L. D. (1954). Thorax

9, 22. .

Evans, W. (1952). Lancet, 2, 1091.

Findlay, L., and Kelly, A. Brown (1931). Proc. roy. Soc. Med., 240 1561 .

Forssell, G. (1912). Münch. med. Wschr., 59, 1588.

Gold, H., and Hatcher, R. A. (1926). J. Pharmacol., 28, 209.

Gubaroff, A. von (1886). Arch. Anat. Physiol. (Anat. Abt.), Lpz p. 395 .

Harman, J. B. (1952). Brit. med. J., 1, 941.

Harrington, S. W. (1940). Amer. J. Surg., n.s., 50, 381.

Hurst, A. F. (1925). Arch. Mal. Appar. dig., 15, 1.

(1943). J. Laryng., 58, 60.

- and Rake, G. W. (1930). Quart. J. Med., 23, 491.

Jackson, Chevalier (1922). Laryngoscope, St. Louis, 32, 139.

Johnstone, A. S. (1952). Proc. roy. Soc. Med., 45, 286.

Lawler, N. A., and McCreath, N. D. (1951). Lancet, 2, 369.

Lendrum, F. C. (1937). Arch. intern. Med., 59, 474.

Lerche, W. (1950). The Esophagus and Pharynx in Action. Thomas Springfield, Ill.

Lewis, F. T. (1912). Amer. J. Anat., 13, 477.

Monro, A. K. (1944). Postgrad. med. J., 20, 273.

Mosher, H. P. (1923). Trans. Amer. Laryng. Ass., 45, 58.

- (1930). J. Laryng., 45, 161.

Negus, V. E. (1936). Ibid., 51, 100.

(1943). Ibid., 58, 46.

Payne, W. W., and Poulton, E. P. (1923). Quart. J. Med., 17, 53. 음

Ramond, Borrien, and Jacquelin, C. (1921). Bull. Soc. anat., Paris 6 ser., $18,204$.

Roux, J. (1939). Bronchoscopie, 2, 81.

Schatzki, R. (1932). Fortschr. Röntgenstr., 45, 177.

Smithers, D. W. (1945). Brit. J. Radiol., 18, 199.

Terracol, J. (1938). Les maladies de l'Oesophage. Masson, Paris. Terracol, J. (1938). Les maladies de l'Oesophage. Masson, Paris.
Willis, T. (1674). Pharmaceutice Rationalis, Part I. Oxford ares

Wooler, G. H. (1952). Proc. roy. Soc. Med., 45, 290. 